\title{
Dois gêneros novos de Eucerinae Neotropicais (Hymenoptera, Apoidea) $^{1}$
}

Danúncia Urban

\begin{abstract}
In this paper, two new genera and species of Neotropical Eucerinae (Hymenoptera, Apoidea) are described: Santiago mourei, gen.n., sp.n. (from Paraopeba, MG, Brazil) and Hamatothrix silvai, gen.n., sp.n. (from Santiago del Estero, Argentina).
\end{abstract}

\section{Santiago gen $\mathbf{n}$.}

Espécie-tipo: Santiago mourei sp.n.

1) Comprimento total aproximado $14,5^{*}$; b) tegumento brilhante com micro-reticulação fraca no clípeo e área supra-clipeal, pontuação densa e grossa no clípeo e paroculares inferiores, muito rasa nas paroculares superiores; densa e grossa no mesosoma com os intervalos lisos e planos no mesoscuto e escutelo; densa porém muito fina nos tergos; grossa e densa na base do propódeo com sulco mediano orlado por tegumento micro-reticulado mate, brilhante e liso no restante do propódeo; c) pilosidade densa e longa na cabeça, mesosoma e base do primeiro tergo, curta e decumbente no restante dos tergos inclusive do primeiro. Fêmeas com pilosidade diferenciada na face ventral dos mesepisternos, os pêlos curto-plumosos na porção apical: fêmur mediano com pêlos levemente arqueados para o meio ao longo do bordo posterior; trocânter posterior com pêlos levemente arqueados para fora, um pouco mais longos que os do fêmur e neste os pêlos com a ponta encurvada para fora; escopas densas, de pêlos predominantemente lisos e longos, com alguns plumosos longos no lado externo do basitarso; lado proximal da tíbia posterior com estria curto-argênteo pilosa, mais larga apicalmente e estreitada para a base, terminando próximo do terço anterior da tíbia. Macho com pêlos curtos no bordo posterior do trocânter e fêmur posteriores. 2.a) Comprimento da cabeça quase $3 / 4$ da sua largura $(3,25: 4,33)$; olhos quase tão longos como a face, convergentes para baixo e mais largos que a metade do seu comprimento; b) clípeo fortemente abaulado e protuberante, separado dos olhos, na altura dos ângulos laterais, por uma distância maior que a metade do diâmetro mínimo do 1 ? flagelômero; c) área supraclipeal protuberante, deprimida em direção aos alvéolos antenais; d) área supra-antenal com a linha frontal em forma de sulco terminando em pequena carena entre os alvéolos antenais; e) área parocular inferior protuberante em continuação com o clípeo; e a paro-

1 Contribuição no 613 do Departamento de Zoologia da Universidade Federal do Paraná. Caixa Postal, 19020 - 81504 Curitiba - Paraná. 
cular superior fracamente côncava ao longo do comprimento; carena parocular do vértice até pouco abaixo dos alvéolos antenais; f) vértice sem carena pósocelar porém com um pequeno tubérculo pós-ocelar a cada lado; distância interocelar menor que a ocelocular e distintamente maior que o dobro do diâmetro do ocelo médio $0,70: 0,76: 0,28)$; g) genas de perfil mais estreitas que os olhos, alargando para baixo e de contorno arredondado; área malar muito curta; seu comprimento mínimo $1 / 9$ da largura da mandíbula na base $(0,08: 0,72)$; h) antena do macho longa, escapo obcônico alongado e pouco menor que a distância alveolocelar lateral, primeiro flagelômero o mais curto, com o menor comprimento inferior à metade do maior $(0,16: 0,36)$; demais flagelômeros longos e deprimidos; i) antena da fêmea mais curta que o dobro do comprimento do olho, escapo mais longo que o 1 ? flagelômero, este menor que a soma do 2 ? com o 3 ? , diâmetro máximo do 40 menor que seu comprimento (escapo: 19 flagelômero - $0,80: 0,48)$; j) labro mais largo que longo com emarginação mediana profunda coberta com densa e longa pilosidade; mandibula robusta, atenuada para o ápice, sem dentes porém no macho com a carena interna superior em lâmina projetada terminando de forma arredondada; estípite com cerdas curtas no pente; palpos maxilares com cinco artículos, o 10 muito largo porém curto e o 2 o o mais longo.

3.a) mesoscuto com a linha mesoscutal fraca até pouco além da metade do seu comprimento; sulco escuto-escutelar profundo; escutelo pouco mais longo que $1 / 3$ do mesoscuto, subarqueado em perfil; metanoto mais curto que a metade do escutelo, sem carena ou sulco mediano; b) asa anterior com 3 células submarginais, bifurcação $\mathbf{M}-\mathbf{C u}$ pouco posterior à cu-a; asa posterior com 12 a 13 hâmulos; c) perna anterior com o esporão estrigilar provido de cerdas grossas curtas na face proximal do ramo distal; placa basitibial com pilosidade curta no macho e sem placa basitibial na fêmea; propódeo quase vertical quando visto de perfil.

4.a) macho com o grádulo do sex to tergo proje tado em forma de dentes; o sétimo tergo sem dentes gradulares, com a placa pigidial truncada e com os lados paralelos no terço apical, a seguir as carenas laterais mais evidentes e divergindo para a base, com pilosidade curta; sex to esterno com pequenas carenas laterais subapicais; sétimo com os apódemas anteriores largos e muito curtos, a placa lateral curta e robusta e a placa média não dividida porém dobrada sobre o esterno; b) sexto tergo da fêmea com placa pigidial lineolada densamente no sentido transversal e com o ápice arredondado.

Comentário - Na chave para os gêneros sulamericanos de Eucerinae, publicada por MOURE \& MICHENER em 1955, o macho entraria no dilema no 27, separando-se de Svastrides pela ausência de pilosidade densa na base do 2 ? e 3 ? tergos, e de Gaesischia pelo clípeo fortemente protuberante, placa pigidial truncada no ápice com lamelas subapicais divergentes. A fêmea entraria no dilema 18 da chave para as fêmeas, separando-se de Gaesischia pela ausência do espinho apical nas coxas anteriores, clípeo fortemente protuberante e comprimento da gálea ultrapassan do o comprimento do olho ( 1,4 vezes).

* Todas as medidas são dadas em milímetros. 


\section{Santiago mourei sp.n.}

Caracteres diagnósticos - Clípeo protuberante e abaulado; a pilosidade predominante amarelo-fulva com o ápice do 1 ? e quase todo o 20 e 30 tergos revestidos por pilosidade curta e lisa, amarelo-fulva; no macho com faixa brancopilosa no 4 e e 5 ọ tergos, afastada do bordo em larga porção do tergo e angulosa porém curta no meio; placa pigidial com recorte lateral; fêmea com área triangular revestida com pêlos amarelo-fulvos no 4 ? tergo, longa porém ocupando somente o meio do tergo.

Holótipo macho: 1. Tegumento predominante prêto, com: a) labro castanho nos flancos, clípeo apicalmente castanho muito pálido, com faixa subapical amarela larga e tríquetra; mancha subapical amarelo-fulva nas mandíbulas; antenas de côr castanha em quase todo o 1 o flagelômero e até o distal; b) tégulas translúcidas, castanho-claras; pernas castanho-amareladas nos artículos distais a partir da porção apical das tíbias; c) tergos e esternos com larga margem translúcida castanho-amarelada.

2. Pilosidade: a) branca na cabeça passando a levemente cremosa junto às antenas e no ocipício; b) amarelo-fulva no mesoscuto e no escutelo e de um tom mais pálido no bordo posterior destes dois escleritos, no propódeo, lobos pronotais e adjacências dos mesepisternos; no restante dos mesepisternos branca inclusive nas pernas, com as cerdas tarsais e basitarsais amarelo-acastanhadas e parte das tíbias médias e posteriores também com pélos desta côr; c) cremosa na base e disco do primeiro tergo, um pouco mais longa no disco, com estreita faixa apical de pêlos curtos e lisos amarelo-fulvos; 2 ? e 30 com pêlos plumosos brancos na base, formando faixa mais larga no 3 ? e o restante destes tergos com pêlos finos e curtos, amarelo-fulvos em arco recurvo; 40 e 50 com pilosidade branca plumosa curta em quase todo o tegumento porém no 40 chegando ao ápice somente nos flancos deixando área apical estreita nos lados e subitamente larga no meio com pélos curtos e lisos amarelo-fulvos; no 5 ? deixando pequena área apical lisa mediana; 6 ? com pêlos plumosos cremosos em vez de brancos, com pequena área apical lisa mediana; 70 amarelo-fulva até na placa pigidial. Cerdas arqueadas cremosas curtas de permeio na pilosidade branca e cerdas longas mais eretas cremosas do 30 ao 5 . Esternos com pilosidade curta amarelo-fulva esparsa, porém longa e semi-ereta nos cantos do 3 ? ao 5 , sem formar franja no bordo dos esternos; pêlos muito curtos do 6 ? fuscos.

3. Características estruturais: a) palpos maxilares com 5 artículos, o $20_{0}$ mais longo; antenas sem carenas ou sulcos ao longo dos flagelômeros; b) fêmur anterior com pilosidade tão longa como sua largura máxima; c) basitarso posterior longo porém não alargando distalmente; d) placa pigidial com pilosidade decumbente muito densa na porção apical, lateralmente marcada por um pequeno recorte estreitando-a no seu terço apical, e sem pêlos na linha mediana; e) sexto esterno com carenas laterais convergentes para o ápice e pilosidade mi.ito curta ao longo da linha média; 70 com a placa média dobrada perpendicularmente à face dorsal do mesmo resultando assimetria no desenho porque a placa fica distendida quando vista ventralmente sôbre lâmina.

4. Largura máxima da cabeça 4,33 ; largura do metasoma 5,42; comprimento da asa, a partir do esclerito costal, 9,50; comprimento do olho 2,36; dis- 
tância interorbital superior 2,52; distância interorbital inferior 2,40; comprimento máximo dos três primeiros flagelômeros $0,20: 1,20: 0,96$; diâmetro máximo do 4 ? flagelômero 0,28 .

Variações - Labro amarelo no disco e castanho nos flancos, no parátipo macho (não foi vista a porção central do labro do holótipo); clípeo com a mancha amarela subapical de contorno basal apenas sinuado, levemente marcado por três convexidades e com a pilosidade predominante cremosa em vez de fulva, inclusive no metasoma. Nas fêmeas foi observada pilosidade mais cremosa, em vez de amarelo-fulva e ausência de mancha subapical amarela nas mandíbulas.

Alótipo fêmea: 1. Tegumento preto, com as seguintes áreas claras: a) mancha subapical amarelo-fulva alongada nas mandibulas; flagelômeros castanhos por baixo, a partir do segundo até o apical; b) pernas castanho-amareladas nos tarsômeros médios e distais, tégulas translúcidas castanho-amareladas; c) larga margem translúcida amarelo-fulva nos tergos e esternos.

2. Pilosidade: a) branca na cabeça passando a cremosa junto às antenas $e$ no ocipício; b) amarelo fulva nos lobos pronotais, mesoscuto e escutelo, um pouco mais clara no ápice do mesoscuto, no propódeo e nos mesepisternos; amarelo-fulva nas pernas passando para cremosa no lado externo da tíbia e do basitarso posteriores; c) cremosa e longa na base e disco do primeiro tergo, estendendo-se até o bordo nos flancos; restante do primeiro tergo com pêlos curtos, finos e esparsos, amarelo-fulvos; base do 20 e do 39 com pêlos plumosos esbranquiçados formando faixa muito estreita no 2 e e com a faixa mais larga nos lados do 3 ?, disco e ápice com pêlos finos, decumbentes de um amarelo-fulvo escuro; 4 ? tergo com pélos plumosos de cor cremosa e somente uma área triangular longa mediana com pélos finos amarelo-fulvos; 5 ? com os pêlos plumosos esbranquiçados na base, e fímbria de um amarelo-fulvo escuro com pêlos longos ramificados; 60 fulvo-acastanhado. Cerdas arqueadas de permeio na pilosidade plumosa no $2 \%$ e $3 \%$, e cerdas longas semi-decumbentes no 40 e 50 tergos. Nos esternos amarelo-fulva, ereta no disco do 10 e $2 \%$; semi-decumbente no $3 \%$ e 40 formando franja subapical, deixando a margem lisa glabra e tufos laterais esparsos; no 5 o longa e densa e no distal densa porém curta.

3. Sem espinho apical nas coxas anteriores.

4. Largura da cabeça: 4,33; largura do metasoma; 5,50; comprimento da asa a partir do esclerito costal: 9,33 ; comprimento do olho: 2,00 ; distância interorbital superior: 2,72 ; distância interorbital inferior: 2,60 .

Material - tipo: Holótipo macho com as seguintes etiquetas: Paraopeba, MG, Brasil / Data 05/05/1987 / F.A. Silveira e 300/762. Alótipo fêmea e cinco parátipos da mesma localidade e coletados por F.A. Silveira, sendo o alótipo e dois parátipos fêmeas em 06/05/1987 e um parátipo macho e dois parátipos fêmeas em 08/05/1987. Um parátipo fêmea de Lagoa Santa, MG, coletado por M. Alvarenga em 09/V/1957. Todos depositados no Departamento de Zoologia da Universidade Federal do Paraná.

Tanto o gênero como a espécie são dedicados ao Prof. Pe. Jesús Santiago Moure pelo seu amplo conhecimento dos Apoidea Neotropicais, pelas suas publicações neste campo da pesquisa e pelos 50 anos de sua primeira publicação em Entomologia. 


\section{Hamatothrix gen.n.}

Espécie-tipo: Hamatothrix silvai sp.n.

1. a) Comprimento total aproximado 8,17 ; b) tegumento brilhante, micro-pontuado, pontuação da cabeça mais esparsa na metade basal do clípeo no macho e, na fêmea a pontuação mais densa no clípeo passando para esparsa somente junto ao sulco epistomal; fina na metade apical do mesoscuto e no escutelo com os intervalos planos; densa nos tergos deixando margem fina desprovida de pontos; densa, grossa e irregular na base do propódeo, com um sulco mediano raso, lineolado longitudinalmente e brilhante e liso no restante, porém levemente bigiboso na porção basal; c) pilosidade densa e longa na cabeça, mesosoma e primeiro tergo (base), mais curta e decumbente no restante dos tergos inclusive do primeiro e nos esternos; mais curta e fina e esparsa na metade ventral dos mesepisternos das fêmeas; esternos dos machos com cerdas curtas levemente encurvadas e os esternos das fêmeas (do 2 ? ao 5 ?) com cerdas curtas não afinando para o ápice, semi-eretas ou eretas, com a porção distal encurvada $\mathrm{e}$, além destas, cerdas mais longas semi-decumbentes arqueadas levemente desde a base formando franjas subapicais do 20 ao 4 ? esterno.

2. a) Comprimento da cabeça nitidamente inferior a $3 / 4$ da sua largura máxima $(2,79: 1,83)$; olhos quase tão longos como a face, convergentes para baixo e mais largos que a metade do seu comprimento; b) clípeo fracamente protuberante, separado dos olhos, na altura dos ângulos laterais, por uma distância menor que o diâmetro mínimo do 1 o flagelômero; c) área supraclipeal quase plana no meio, deprimida junto aos alvéolos antenais; d) área supra-antenal com a linha frontal em forma de curta carena entre os alvéolos antenais e pouco acima dos mesmos; e) área parocular inferior quase plana, a parocular superior levemente côncava ao longo do seu comprimento, carena parocular fraca do ápice da fronte (na altura do ocelo médio) até a área malar; f) vértice sem carena pósocelar, porém com um pequeno tubérculo pós-ocelar a cada lado; distância interocelar muito maior que a ocelocular e esta pouco menor que o dobro do ocelo médio $(0,58: 0,40: 0,22) ; \mathrm{g})$ genas de perfil mais estreitas que os olhos e de contorno arredondado uniforme; área malar muito curta, seu comprimento mínimo $1 / 10$ da largura da mandibula na base $(0,03: 0,34)$, um pouco maior na fêmea; h) antena do macho longa, escapo obcônico alongado, menor que a distância alveolocelar lateral $(0,54: 0,72)$, o 1 ? flagelômero o mais curto, com o comprimento menor um pouco inferior a $3 / 4$ do maior $(0,19 / 0,28)$; demais flagelômeros longos e não deprimidos; i) antena da fêmea mais curta que o dobro do comprimento dos olhos, escapo medindo o dobro do comprimento do 1 ? flagelômero, este menor que a soma do 2 com o 3 o e o diâmetro do 4 ? flagel ômero quase igualando seu comprimento (escapo: 1 ? flagelômero - 0,67:0,33); j) labro mais largo que longo, com emarginação mediana rasa coberta com pilosidade; mandíbula robusta, atenuada para o ápice, sem dentes; estípite com cerdas curtas no pente; palpos maxilares com cinco artículos, o 1 o largo e curto e o $20_{0}$ mais longo.

3. a) Mesoscuto com a linha mesoscutal ocupando apenas o terço basal; sulco escuto escutelar profundo; escutelo medindo $2 / 5$ do comprimento do mesoscuto, muito arqueado quando visto de perfim, quase plano; metanoto medin- 
do $1 / 4$ do comprimento do escutelo, sem carena ou sulco mediano; b) asa anterior com 3 células submarginais, bifurcação entre $\mathbf{M}-\mathbf{C U}$ pouco posterior à cu-a; asa posterior com 10 a 11 hâmulos; c) perna anterior com o esporão estrigilar desprovido de cerdas grossas; placa basitibial do macho com pilosidade curta (incompleta anteriormente) e na fêmea com o bordo inteiramente exposto; propódeo arredondado quando visto de perfil.

4. a) Macho com o grádulo do sex to tergo projetado em forma de dentes e o sétimo tergo sem dentes gradulares, com a placa pigidial densamente pilosa, truncada no ápice e alargando para a base; sexto esterno sem carenas ou tubérculos; 70 com os apódemas anteriores curtos, placa lateral curta e robusta, placa média não dividida e nem dobrada sobre o restante do esterno e com pilosidade curta; b) sexto tergo da fêmea com placa pigidial arredondada no ápice e lineolada irregularmente.

Comentário - Na chave anteriormente citada o macho deste gênero entraria no dilema no 22, concordando somente em parte: 6 ? esterno sem carenas convergentes porém com área médio-basal elevada, separando-se de Dasyhalonia por não apresentar as demais características citadas na chave, ou seja, com o lado interno do fêmur mediano piloso, emarginação labral rasa e largura dos flagelômeros igualando o diâmetro do ocelo médio. A fêmea entraria no dilema no 7: com a placa basitibial inteiramente exposta, porém distinguindo-se de Florilegus pela ausência de projeções dentiformes no grádulo do 6 ? tergo.

A denominação genérica, do grego, significa: pêlos em forma de gancho.

\section{Hamatothrix silvai sp.n.}

Caracteres diagnósticos: - Macho com pilosidade branco-cremosa na cabeça e mesosoma, e no metasoma enegrecida; labro e clípeo amarelos; sex to esterno sem carenas, com pilosidade curta no meio formando um tufo alargado para a base e para o ápice. Fêmea com o labro amarelo e o clípeo com mancha trilobulada amarela; pilosidade esbranquiçada na cabeça e mesosoma, porém o que mais a caracteriza é a presença de cerdas arqueadas nos esternos, numerosas e mais curtas no disco dos mesmos.

Holotipo macho - 1. Tegumento predominante preto, com as seguintes áreas claras: a) clípeo, labro e metade das mandíbulas amaralo-claro, no clípeo com duas pequenas nódoas castanhas junto às fóveas tentoriais anteriores e nas mandibulas mancha subapical de um amarelo intenso; antenas com os artículos castanho-enegrecidos por cima e castanho-claros a partir do segundo flagelômero, por baixo; b) tégulas translúcidas de um castanho-claro, pernas também desta cor nas tíbias e tarsômeros, os artículos basais castanhos; c) tergos enegrecidos com margem translúcida castanho-amarelada e esternos castanhos com margem translúcida estreita amarela.

2. Pilosidade: a) branco cremosa na cabeça e no (b) mesosoma, levemente acastanhada nas pernas; c) esbranquiçada e longa na base e no disco do primeiro tergo; ápice do 10 e os tergos seguintes até o 5 o com pilosidade castanho-escura fina e curta, nos cantos basais do 2 \% ao 4 \% com pêlos plumosos curtos brancos; 

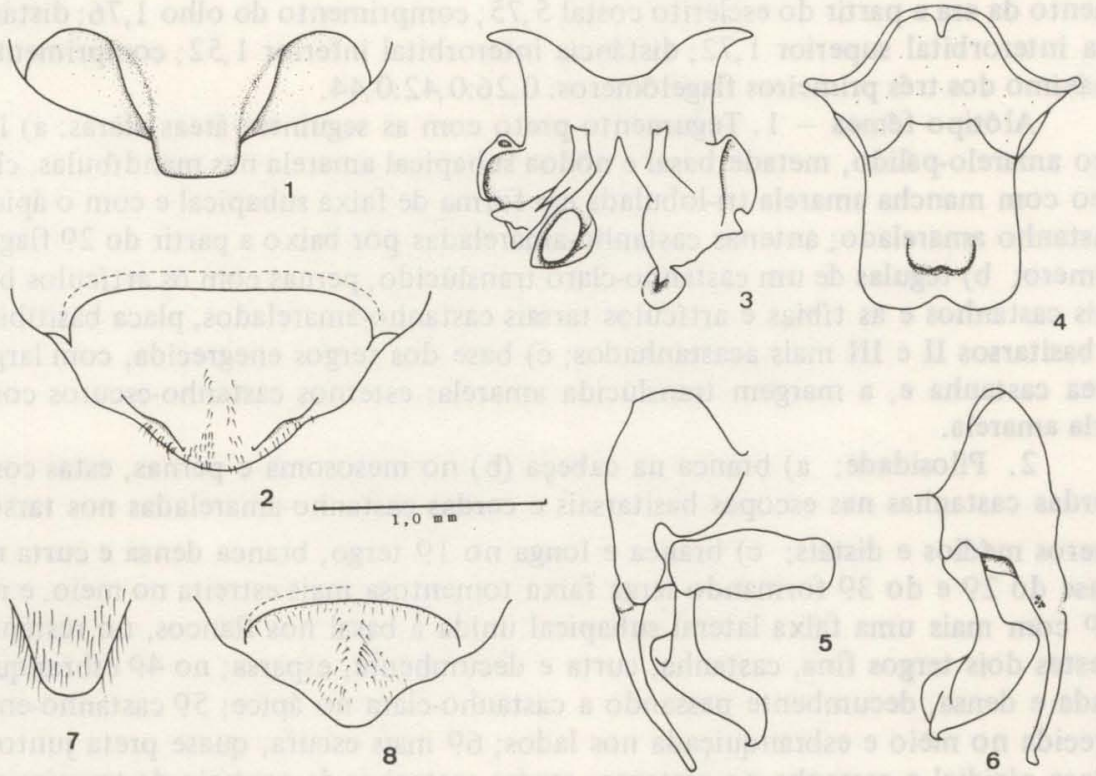

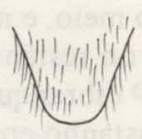

7

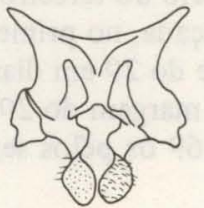

9

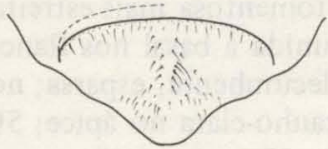

8

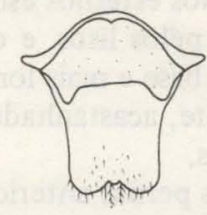

10
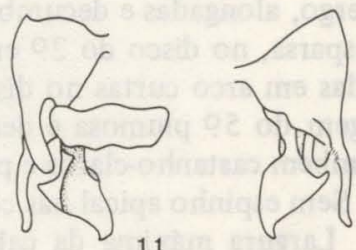

12

- Detalhes estru turais dos machos de: 1-6, Santiago mourei, gen. n., sp. n. e 7-12, Hamatothrix silvai, gen. n., sp. n.: 1 e 7, ápice do 70 tergo; 2 e 8, ápice do 6 ? esterno; 3 e 9, sétimo esterno, com o lado dorsal na metade esquerda; 4 e 10, lado dorsal do 80 esterno; 5 e 11 , vista dorsal de parte da genitália; 6 e 12 , vista ventral de metade da genitália, sem gonobase.

no 60 alongada e enegrecida; cerdas esparsas de permeio no 40 e 50 . Esternos com pêlos lisos castanhos e curtos; do 2 ? ao 4 ? com franjas laterais de pélos branco-plumosos, as franjas mais alongadas nos lados.

3. Características estruturais: a) palpos maxilares com 5 artículos, antenas sem carenas ou sulcos ao longo dos flagelômeros; b) fêmur anterior com pilosidade pouco mais longa que sua largura máxima; c) basitarso posterior não alargado distalmente; d) placa pigidial com pilosidade decumbente muito densa; e) sex to esterno sem carenas, com área pilosa mediana mais larga na base e no ápice, os pêlos curtos e semi-eretos. 
4. Largura máxima da cabeça 2,79 ; largura do metasoma 2,80; comprimento da asa a partir do esclerito costal 5,75 ; comprimento do olho 1,76 ; distância interorbital superior 1,72 ; distância interorbital inferior 1,52 ; comprimento máximo dos três primeiros flagelômeros: 0,26:0,42:0,44.

Alotipo fêmea - 1. Tegumento preto com as seguintes áreas claras: a) labro amarelo-pálido, metade basal e nódoa subapical amarela nas mandíbulas, clípeo com mancha amarela tri-lobulada em forma de faixa subapical e com o ápice castanho amarelado; antenas castanho-amareladas por baixo a partir do 2 ? flage lômero; b) tégulas de um castanho-claro translúcido, pernas com os artículos basais castanhos e as tíbias e artículos tarsais castanho-amarelados, placa basitibial e basitarsos II e III mais acastanhados; c) base dos tergos enegrecida, com larga área castanha e, a margem translúcida amarela; esternos castanho-escuros com orla amarela.

2. Pilosidade: a) branca na cabeça (b) no mesosoma e pernas, estas com cerdas castanhas nas escopas basitarsais e cerdas castanho-amareladas nos tarsômeros medios e distais; c) branca e longa no 10 tergo, branca densa e curta na base do 2 e do 30 formando larga faixa tomentosa mais estreita no meio, e no 30 com mais uma faixa lateral subapical unida à basal nos flancos, no restante destes dois tergos fina, castanha, curta e decumbente, esparsa; no 40 esbranquiçada e densa, decumbente passando a castanho-clara no ápice; 50 castanho-enegrecida no meio e esbranquiçada nos lados; 60 mais escura, quase preta junto à placa pigidial e castanha no restante; cerdas castanhas de permeio do terceiro ao quinto tergo, alongadas e decumbentes. Nos esternos esbranquiçada, no primeiro ereta e esparsa, no disco do 2 ? ereta, os pêlos lisos, e do ápice do 20 em diante com cerdas em arco curtas no disco e na base e mais longas na margem do 2 ? ao 40; margem do 5 ? plumosa e decumbente, acastanhada e no 6 ? os pêlos semieretos também castanho-claros e plumosos.

3. Sem espinho apical nas coxas das pernas anteriores.

4. Largura máxima da cabeça 3,42; largura do metasoma 3,58; comprimento da asa a partir do esclerito costal 4,17 (parátipo); comprimento do olho 1,83; distância interobital superior 2,08; distância interobital inferior 1,83.

Material-tipo - Holótipo macho com a seguinte etiqueta: ARGENTINA Santiago / del Estero, Dpto. / Matará, Desvio 511 / 24 October 1928 / (M. Gomez). Alótipo fêmea, dois parátipos fêmeas e um parátipo macho apenas com a etiqueta indicando Santiago del Estero, ARGENTINA, coletados também por Gomez e etiqueta com o no 22.963; um parátipo fêmea e 4 parátipos machos com a etiqueta igual à do holotipo.

Todos depositados no Departamento de Zoologia da Universidade Federal do Paraná.

A espécie é dedicada ao Prof. Jayme de Loyola e Silva pelos seus trabalhos no campo da Zoologia.

\section{REFERENCIAS}

MOURE, J.S. \& C.D. MICHENER. 1955. A contribution toward the classification of Neotropical Eucerini. Dusenia, 6(6):239-331. 